\title{
CARACTERIZAÇÃO FÍSICO-QUÍMICA, HISTOLÓGICA E VIABILIDADE DE BACTÉRIAS LÁCTICAS EM IOGURTES COM FRUTAS ${ }^{1}$
}

\author{
Maria Auxiliadora de Brito RODAS ${ }^{2, *}$, Regina Maria Morelli Silva RODRIGUES ${ }^{2}$, \\ Harumi SAKUMA ${ }^{2}$, Lana Zanetti TAVARES ${ }^{3}$, Cássia Regina SGARBI ${ }^{3}$, Welitania C.C. LOPES ${ }^{3}$
}

\begin{abstract}
RESUMO
Foram analisadas 136 amostras de iogurtes com frutas de 8 marcas diferentes, adquiridas em supermercados da cidade de São Paulo, no período de 1997 a 1998, com a finalidade de caracterizá-los quanto aos parâmetros físico-químicos, identificação histológica das frutas adicionadas e viabilidade de bactérias lácticas viáveis. Nas avaliações foram utilizadas metodologias oficiais e recomendações. Quanto aos parâmetros físico-químicos, os resultados obtidos das variações médias e desvio padrão foram os seguintes: $\mathrm{pH}(4,01 \pm 0,11)$; substâncias voláteis $(77,91 \% \pm 1,85)$; resíduo mineral fixo $(0,68 \% \pm 0,10)$; lipídios $(1,95 \% \pm 0,65)$; proteínas $(2,95 \% \pm 0,46)$; carboidratos totais $(15,89 \% \pm 1,44)$ e valor calórico $(93 \pm 9)$. Das 136 amostras analisadas, detectou-se fraude em $5,8 \%$ por não apresentarem as frutas indicadas na rotulagem, em $40,4 \%$ por apresentarem elementos histológicos de vegetais não discriminados pelos fabricantes e $44,1 \%$ por conterem fungos filamentosos, indicativo de utilização inadequada de matéria-prima. Quanto à viabilidade das bactérias lácticas, verificou-se a positividade da fermentação em até a diluição $10^{-7}$ em todas as amostras, mesmo naquelas que apresentavam apenas cocos Gram-positivos. $\mathrm{Na}$ contagem individual de estreptococos e de lactobacilos constituintes da microbiota láctica, $31,73 \%$ das amostras apresentaram quantidade igual ou superior a $10^{7} \mathrm{UFC} / \mathrm{mL}$, limite mínimo indicado pela Recomendação Mercosul n 31/97.
\end{abstract}

Palavras-chave: iogurtes com frutas; composição nutricional e valor calórico; identificação histológica; viabilidade de bactérias lácticas.

\section{SUMMARY}

PHYSICO CHEMICAL, HISTOLOGYCAL AND VIABILITY OF LACTIC BACTERIA IN YOGURTS CONTAINING FRUIT. One hundred and thirty six (136) samples of yogurts with fruits from eight different brands, acquired in supermarkets of São Paulo, in the period betwen 1997 and 1998, have been analysed aiming to characterise them for physico-chemical parameters, histologycal identification of added fruits and viability of lactic bacteria. On valuation official methodologies and recommendations were used . Concerning the physico-chemical parameters, the obtained results for medium verification and standard deviation were as follows: $\mathrm{pH}(4.01 \pm 0.11)$; volatile substances $(77.91 \% \pm 1.85)$; fixed mineral residue $(0.68 \% \pm 0.10)$; lipids $(1.95 \% \pm 0.65)$; protein $(2.95 \% \pm 0.46)$; total carbohydrates $(15.89 \% \pm 1.44)$ and caloric value $(93 \pm 9)$. From the 136 samples analyzed, fraud was detected in $5.8 \%$ for not containing the fruits indicated in the label, in $40.4 \%$ for containing hystological elements of vegetables not discriminated by the

\footnotetext{
${ }_{1}^{1}$ Recebido para publicação em 09/08/00. Aceito para publicação em 05/10/01.

2 INSTITUTO ADOLFO LUTZ, Diretoria de Serviço de Alimentos, Seção de Laticínios, Seção de Microscopia e Seção de Microbiologia Alimentar. Av. Dr. Arnaldo, 355, CEP: 01246-902, São Paulo, SP. ${ }^{3}$ Bolsistas da Secretaria da Saúde do Estado de São Paulo Programa de Aprimoramento Profissional do Instituto Adolfo Lutz - PAP/IAL.

${ }^{*}$ A quem a correspondência deve ser enviada.
}

manufacturer and in $44.1 \%$ for containing filamentous fungi, a signal of bad usage of the raw material. The positivity of fermentation in a dilution of up to 10 was verified with regard to the viability of lactic bacteria even in those samples which had only cocci Granpositives. In the individual counting of sterptococci and lactobaccilli, $31.73 \%$ of the samples had at least $10^{7} \mathrm{UFC} / \mathrm{mL}$, the minimum limit indicated by "Recomendação Mercosul n 31/97".

Keywords: yogurts with fruits; nutritional composition and caloric value; histologyc identification; viability of lactic bacteria.

\section{1 - INTRODUÇÃO}

O iogurte, produto da fermentação láctica, está presente na dieta alimentar humana desde os tempos remotos, quando a fermentação era utilizada como forma de preservação do leite $[1,11,17]$.

As culturas lácticas são utilizadas para aumentar a vida-de-prateleira do leite, devido à formação de componentes metabólicos como ácido láctico, ácido propiônico, diacetil e substâncias antagonísticas que exercem efeito inibitório nas bactérias Gram-negativas responsáveis pela deterioração do produto [12, 19, 21].

Na produção dos iogurtes, normalmente empregase cultura mista de Lactobacillus delbrueckii ssp bulgaricus e Streptococcus thermophilus [5]. Estas bactérias se mantêm em crescimento associado ou culturas separadas que são inoculadas no leite em proporções definidas [1, 12, 20]. Geralmente, utiliza-se a proporção de $1: 1$ (cocos para bacilos), que definem as características reológicas e aromáticas ideais [17].

As bactérias lácticas, em convívio simbiótico [5, 18, 20], estimulam-se mutuamente, complementando o crescimento uma da outra [12]. No início da fermentação, o $\mathrm{pH}$ do leite favorece o desenvolvimento do Streptococcus thermophilus [20]. Com o aumento da acidificação, ou seja, do teor de ácido láctico a partir da lactose, crescem os Lactobacillus delbrueckii ssp bulgaricus. Estes são proteolíticos, obtêm aminoácidos a partir da caseína (glicina, histidina, valina) e ativam o crescimento dos estreptococos que, por sua vez, estimulam o crescimento dos lactobacilos, com a produção de ácido fórmico e gás carbônico [12, 20].

Procura-se manter o equilíbrio adequado das bactérias, para que o produto permaneça suficientemente ácido e aromático [20]. A acidez torna os iogurtes alimentos relativamente estáveis por inibir o crescimento de bactérias Gram-negativas, onde o $\mathrm{pH}$ pode variar de 3,6 a 4,2 [19], podendo atingir $\mathrm{pH}$ final de até 4,5 [9].

Durante a fermentação, a proteína, a gordura e a lactose do leite sofrem hidrólise parcial, tornando o produto facilmente digerível, sendo considerado agente 
regulador das funções digestivas $[1,7,11,20]$. A acidez própria estimula as enzimas digestivas pelas glândulas salivares. Certas características são benéficas para indivíduos com intolerância à lactose e tendências à hiperglicemia pós-prandial [11]. Outras propriedades também se relacionam aos iogurtes, como os efeitos anticolesterolêmicos, anticarcinogênicos, inibitórios de agentes patógenos, entre outros [11, 16].

A legislação brasileira (Decreto $n^{\circ} 2.244 / 97$ ) [4] define o iogurte como "o produto obtido pela fermentação lática através da ação do Lactobacillus delbrueckii ssp bulgaricus e Streptococcus thermophilus sobre o leite integral, desnatado ou padronizado". Pode-se fazer acompanhar de outras bactérias lácticas que, por sua atividade, contribuem para a determinação das características do produto acabado $[5,6]$.

O leite empregado no processamento do iogurte deve ser de boa procedência e qualidade, pois é responsável pelo seu valor nutricional $[1,11,17]$. Deve passar por tratamento térmico (pasteurização ou tratamento UAT - Ultra Alta Temperatura), a fim de eliminar microrganismos patogênicos e destruir as substâncias inibidoras do crescimento bacteriano presentes no leite cru como as aglutininas [1, 20].

O iogurte é um produto amplamente recomendado pelas suas características sensoriais, probióticas e nutricionais [17], pois, além de ser elaborado com leite contendo alto teor de sólidos, cultura lática e açúcar, pode ainda, ser enriquecido com leite em pó, proteínas, vitaminas e minerais, e ser produzido com baixo teor ou isento de gordura $[11,20]$.

A produção mundial e o consumo de iogurtes cresceram muito durante o último quarto deste século, com a introdução dos iogurtes aromatizados com frutas [1, 7]. A adição de frutas aumenta de maneira eficaz a aceitação do produto, pois nem todos os consumidores preferem o iogurte na sua forma natural [18].

Tem havido constante sofisticação tecnológica com surgimento crescente de novos produtos no mercado $[9,12]$, onde os fabricantes preocupam-se em diversificar sabores e aromas utilizando essências, extratos de frutas e/ou frutas preparadas de uma ou mais espécies $[1,9,17,19,20]$. Nos casos da adição dos ingredientes permitidos, o conteúdo de iogurte não deve ser inferior a $70 \%$ do peso total do produto [6].

A literatura brasileira é escassa em dados que levem à caracterização dos iogurtes, principalmente dos adicionados com frutas, não havendo até o presente, estabelecimento de normas legais regulamentadas sobre a composição nutricional e calórica, apesar da grande variedade de tipos e sabores encontrados no mercado.

A finalidade deste trabalho consistiu na caracterização dos iogurtes com frutas, em relação aos parâmetros físico-químicos, identificação histológica das frutas empregadas no processamento e a contagem de lactobacilos e estreptococos.

\section{2 - MATERIAL E MÉTODOS}

\section{1 - Material}

No período de 1997 a 1998, adquiriram-se, em supermercados da cidade de São Paulo, 136 amostras de iogurtes com frutas de 8 marcas e/ou fabricantes diferentes, que foram codificadas por letras (A, B, C, D, $E, F, G$ e H). As frutas adicionadas aos iogurtes, utilizadas individualmente ou combinadas em duas ou mais, em pedaços, em polpas ou sucos, foram: abacaxi, morango, maracujá, maçã, melão, mamão, framboesa, uva, amora, banana, laranja, limão, tangerina, kiwi, coco e pêssego.

Como fatores limitantes na aquisição das amostras de iogurte considerou-se o prazo de validade, o lote de fabricação e as condições adequadas de refrigeração nos supermercados. As amostras foram transportadas em caixas de isopor até o laboratório, dandose início à análise microbiológica. Para as determinações físico-químicas e histológicas, as amostras foram conservadas em geladeira por um período máximo de $24 \mathrm{~h}$, até o início das análises.

\section{2 - Métodos}

\subsubsection{Avaliação da composição nutricional e calórica}

Constou das seguintes determinações físico-químicas: $\mathrm{pH}$ (potenciômetro calibrado com soluções tampão de pH 4,0 e 7,0); substâncias voláteis após a evaporação (banho-maria fervente e estufa convencional a $85^{\circ} \mathrm{C}$ ); resíduo mineral fixo da amostra calcinada (forno-mulfla a $550^{\circ} \mathrm{C}$ ); proteína (método de Kjeldahl) pela determinação do nitrogênio total (cálculo utilizando fator 6,38 ) e carboidratos totais calculados em glicose (método de Lane-Eynon) após hidrólise em meio ácido (ácido clorídrico) sob refluxo por $3 \frac{1}{2}$ horas. Nas determinações físico-químicas foram utilizadas as metodologias descritas nas Normas Analíticas do Instituto Adolfo Lutz [10] e nos Métodos Analíticos Oficiais do Ministério da Agricultura [13]. A determinação de lipídios foi realizada após hidrólise ácida (ácido clorídrico a $60 \%$ ), secagem e extração com éter de petróleo (P.E. $40-60^{\circ} \mathrm{C}$ ) sob refluxo por $3 \frac{1}{2}$ horas, segundo o Método Oficial do Ministério da Educação (FAE) [14]. Calculou-se o valor calórico considerando-se os fatores clássicos de Atwater, ou seja, os teores de proteínas e carboidratos multiplicando-se por 4,0 e os teores de lipídios, por 9,0 [8].

\subsection{2 - Identificação histológica}

No isolamento dos constituintes vegetais presentes nas amostras dos iogurtes, utilizou-se o método de tamisação [15] que faz uso do Tamis USBS-230. Para a identificação dos elementos histológicos característicos das frutas, o material tamisado foi observado ao microscópio ótico (aumento de 100 a 400 X). Esta metodologia analítica possibilita também a verificação da presença de matéria estranha, além da observação de 
hifas eventualmente presentes nas estruturas celulares da(s) fruta(s).

\subsection{3 - Contagem de bactérias lácticas}

Alíquota de $25 \mathrm{~mL}$ da amostra do iogurte foi colhida em $225 \mathrm{~mL}$ de Água Peptonada a 0,1\% (diluição $10^{-1}$ ), homogeneizada, e diluições sucessivas $\left(10^{-2}\right.$ a $\left.10^{-7}\right)$ foram efetuadas em $9 \mathrm{~mL}$ de Água Peptonada a 0,1\%. Para a verificação da atividade das bactérias lácticas (coagulação do leite estéril) foram semeados $1 \mathrm{~mL}$ de cada uma das diluições $10^{-5}, 10^{-6}$ e $10^{-7}$, em tubos contendo $10 \mathrm{~mL}$ de leite estéril, e incubados a $35^{\circ} \mathrm{C} / 48 \mathrm{~h}$. Após incubação, fez-se a coloração de Gram para verificar a presença/ausência de cocos e bacilos Grampositivos por diluição associada à coagulação do leite. Paralelamente, para a contagem das bactérias lácticas, efetuou-se a semeadura em profundidade das mesmas diluições $\left(10^{-5}, 10^{-6}\right.$ e $\left.10^{-7}\right)$ em meio de cultura Ágar Diferencial para Lactobacillus bulgaricus/Streptococcus thermophilus (L-S Differential Medium), descrito em Microbiologia Alimentaria - Metodologia Analítica para Alimentos y Bebidas" [2]. Incubou-se a $42^{\circ} \mathrm{C} / 48 \mathrm{~h}$, em seguida, efetuou-se, separadamente, as contagens das colônias características de lactobacilos e de estreptococos e a coloração de Gram.

\subsection{4 - Análise estatística}

Os resultados obtidos nas determinações físicoquímicas (composição nutricional e valor calórico) das 136 amostras de iogurtes, com frutas avaliadas por marca, foram tratados estatisticamente pela análise de variância e teste de média de Tukey $(p<0,05)$, utilizando-se o programa computadorizado SAS (Statistical Analysis System) versão 6.2.

\section{3 - RESULTADOS E DISCUSSÃO}

Os resultados obtidos das determinações físicoquímicas das amostras de iogurtes com frutas, por marca codificada, são apresentados na Tabela 1 e as variáveis médias destes resultados encontram-se na Tabela 2.

TABELA 1. Resultados médios das determinações físico-químicas dos iogurtes com frutas, por marca codificada. SP, 1999.

\begin{tabular}{|c|c|c|c|c|c|c|c|c|}
\hline \multirow[t]{2}{*}{ Determinações } & \multicolumn{8}{|c|}{ Marcas } \\
\hline & A & B & $\mathrm{C}$ & D & $\mathrm{E}$ & $\mathrm{F}$ & G & $\mathrm{H}$ \\
\hline $\mathrm{pH}$ & $4,02^{\mathrm{a}}$ & $3,99^{\mathrm{ab}}$ & $4,02^{\mathrm{a}}$ & $3,99^{\mathrm{ab}}$ & $3,89^{b}$ & $4,05^{a}$ & $4,05^{\mathrm{a}}$ & $4,08^{\mathrm{a}}$ \\
\hline Voláteis (g\%) & $79,01^{a}$ & $76,67^{\mathrm{d}}$ & $77,81^{\text {abcd }}$ & $78,41^{\text {abc }}$ & $78,54^{\mathrm{ab}}$ & $77,14 b^{c d}$ & $76,68^{\text {cd }}$ & $78,99^{a}$ \\
\hline Cinzas (g\%) & $0,65^{\mathrm{bc}}$ & $0,67^{\mathrm{bc}}$ & $0,64^{\mathrm{bc}}$ & $0,60^{c}$ & $0,66^{\mathrm{bc}}$ & $0,72^{\mathrm{ab}}$ & $0,77^{\mathrm{a}}$ & $0,73^{\mathrm{ab}}$ \\
\hline Lipídios (g\%) & $1,88^{b}$ & $1,95^{\mathrm{b}}$ & $2,73^{\mathrm{a}}$ & $1,75^{\mathrm{b}}$ & $2,17^{\mathrm{ab}}$ & $1,75^{\mathrm{b}}$ & $1,74^{\mathrm{b}}$ & $1,60^{\mathrm{b}}$ \\
\hline Proteinas (g\%) & $2,81^{\mathrm{bc}}$ & $2,87^{\mathrm{bc}}$ & $3,05^{\mathrm{ab}}$ & $2,51^{\mathrm{c}}$ & $2,81^{\mathrm{bc}}$ & $3,13^{\mathrm{ab}}$ & $3,40^{\mathrm{a}}$ & $3,02^{\mathrm{ab}}$ \\
\hline Carboidratos $^{\star}(\mathrm{g} \%)$ & $15,20^{\text {cd }}$ & $17,41^{\mathrm{a}}$ & $15,10^{d}$ & $15,93^{\mathrm{bcd}}$ & $15,19^{d}$ & $16,47^{\mathrm{abc}}$ & $16,76^{\mathrm{ab}}$ & $15,07^{d}$ \\
\hline Calorias (Kcal\%) & $89^{b c}$ & $99^{\mathrm{a}}$ & $97^{\text {ab }}$ & $90^{\mathrm{abc}}$ & $91^{\mathrm{abc}}$ & $94^{\mathrm{abc}}$ & $96^{\mathrm{ab}}$ & $87^{\circ}$ \\
\hline
\end{tabular}

* Calculados em glicose.

a, b, c, d Médias com letras iguais, em mesma linha, não diferem estatisticamente entre si ao nível de $5 \%$ de significância.

Na Tabela 1, observa-se que as diferentes marcas de iogurtes com frutas apresentaram pouca variação entre os valores de $\mathrm{pH}$. A marca $\mathrm{E}(3,89)$ com menor valor de $\mathrm{pH}$, diferiu significativamente $(\mathrm{p}<0,05)$ das marcas A $(4,02), C(4,02), F(4,05), G(4,05)$ e $H(4,08)$, não diferindo das marcas $B(3,99)$ e $D(3,99)$. Entretanto, verifica-se que todas as marcas encontram-se dentro do limite de $\mathrm{pH}$, no qual o crescimento das bactérias lácticas, desenvolvem-se normalmente e sem prejuízo, ou seja, entre 3,6 a 4,3 [19, 20].

Quanto às substâncias voláteis (Tabela 1), ocorreu maior diferença significativa entre as marcas. A marca $B$ não diferiu significativamente da $\mathrm{G}$, apresentando os menores valores, respectivamente, 76,67 e 76,68g\%. A marca $A(79,01 \mathrm{~g} \%)$ com maior valor não diferiu das marcas $C, D$, E e $H$. A marca $C(77,81 \mathrm{~g} \%)$ não diferiu das demais marcas em relação ao conteúdo em substâncias voláteis.

Para os teores em cinzas, a marca G $(0,77 \mathrm{~g} \%)$ apresentou-se significativamente diferente $(p<0,05)$ das marcas $A, B, C, D$ e $E$, apresentando resíduo mineral fixo mais alto, mas não diferindo de $\mathrm{F}$ e $\mathrm{H}$, respectivamente com valores de 0,72 e $0,73 \mathrm{~g} \%$ (Tabela 1 ).

Ainda na Tabela 1, verifica-se que quanto ao teor em lipídios, as diferentes marcas mostraram variações significativas. A marca C $(2,73 \mathrm{~g} \%)$, com maior conteúdo lipídico, não diferiu da marca $E(2,17 \mathrm{~g} \%)$. As demais marcas $(A, B, D, F, G$ e H) não diferiram entre si e apresentaram conteúdo menor, respectivamente, 1,88; 1,$95 ; 1,75 ; 1,75 ; 1,74$ e $1,60 \mathrm{~g} \%$.

Para as proteínas (Tabela 1), a marca G $(3,40 \mathrm{~g} \%)$ mostrou maior teor e não variou significativamente com relação às marcas $\mathrm{C}, \mathrm{F}$ e $\mathrm{H}$. A marca $\mathrm{D}(2,51 \mathrm{~g} \%)$, com menor teor, não diferiu significativamente das marcas $A, B$ e $E$, tendo estas últimas, valores intermediários. Considerando o limite mínimo de $2,90 \mathrm{~g} \%$ de proteína para os iogurtes, indicado pela Recomendação Mercosul $\mathrm{n}^{\circ} 31 / 97$ [5], as marcas A $(2,81 \mathrm{~g} \%), \mathrm{B}(2,87 \mathrm{~g} \%), \mathrm{D}$ $(2,51 \mathrm{~g} \%)$ e $E(2,81 \mathrm{~g} \%)$ não atenderiam a esta regulamentação.

Os carboidratos totais, avaliados em glicose, apresentaram diferenças significativas $(p<0,05)$ entre as diferentes marcas (Tabela 1). Os teores variaram de $15,07 \mathrm{~g} \%$ (marca $\mathrm{H}$ ) a $17,41 \mathrm{~g} \%$ (marca $\mathrm{B}$ ). A marca $\mathrm{H}$ não diferiu significativamente das marcas $A, C, D$ e $E$, enquanto a marca $B$, com maior teor, não diferiu das marcas $\mathrm{F}$ e $\mathrm{G}$.

De acordo com a Tabela 1, verifica-se que os valores calóricos variaram significativamente $(p<0,05)$ entre as marcas de iogurtes com frutas. A marca $B$ (99Kcal\%), com maior valor calórico, diferiu significativamente das marcas $\mathrm{A}$ e $\mathrm{H}$, com menores valores calóricos, respectivamente, 89 e $87 \mathrm{Kcal} \%$. As demais marcas, C, D, E e G, apresentaram valores calóricos intermediários.

$\mathrm{Na}$ Tabela 2, verificam-se as variações médias obtidas das determinações físico-químicas das 8 marcas de iogurtes com frutas analisadas, cujos valores apresentados podem ser comparados com os limites mínimos propostos pela Recomendação Mercosul n 31/97 [5]. Os teores de lipídios, conforme os produtos sejam 
desnatados, parcialmente desnatados, integrais ou com creme, podem variar de 0,5 até $6,0 \mathrm{~g} \%$ [5]. Desta forma, pode-se dizer que o valor médio obtido, $1,95 \mathrm{~g} \% \pm 0,65$ (Tabela 2) colocaria os iogurtes entre os parcialmente desnatados. A proteína é fixada em no mínimo $2,9 \mathrm{~g} \%$ [5] e, no presente trabalho, obteve-se o teor de $2,95 \mathrm{~g} \% \pm 0,46$ (Tabela 2), valor médio que pode ser considerado ideal para o produto. A Recomendação Mercosul [5] menciona que quanto à adição de açúcares (carboidratos) e demais ingredientes, estes não devem ultrapassar o conteúdo das substâncias lácticas presentes.

TABELA 2. Resultados das variáveis médias das determinações físico-químicas de todas as marcas de iogurtes com frutas analisadas. SP, 1999.

\begin{tabular}{l|cccc}
\hline \multicolumn{1}{c|}{ Determinações } & \multicolumn{4}{c}{ Variáveis } \\
& Média & Desvio padrão & Valor mínimo & Valor máximı \\
& 4,01 & 0,11 & 3,60 & 4,30 \\
$\mathrm{pH}$ & 77,91 & 1,85 & 73,10 & 81,38 \\
Voláteis $(\mathrm{g} \%)$ & 81,38 & 0,10 & 0,50 & 0,92 \\
Cinzas $(\mathrm{g} \%)$ & 1,95 & 0,65 & 1,14 & 3,82 \\
Lipídios $(\mathrm{g} \%)$ & 2,95 & 0,46 & 2,30 & 4,46 \\
Proteínas $(\mathrm{g} \%)$ & 15,89 & 1,44 & 12,41 & 20,84 \\
Carboidratos* $(\mathrm{g} \%)$ & 93 & 9 & 76 & 118 \\
Calorias $($ Kcal \%) & & & & \\
\hline
\end{tabular}

* Calculados em glicose

As diferentes marcas de iogurtes apontam calorias variando do valor mínimo de $76 \mathrm{Kcal} \%$ ao máximo de $118 \mathrm{Kcal} \%$, apresentando valor médio de $93 \mathrm{Kcal} \% \pm 9$ (Tabela 2). A maior ou menor adição de açúcares, o enriquecimento do produto com substâncias que aumentem o teor de sólidos podem, provavelmente, colaborar na variabilidade e aumento do valor calórico dos produtos.

$\mathrm{Na}$ análise microscópica, foram identificados os elementos histológicos dos vegetais característicos, os estranhos ao produto e também as hifas dos fungos filamentosos. Na avaliação microscópica, considerouse cada tipo de ocorrência isoladamente (ausência da fruta característica, presença de vegetal estranho e presença de fungos) ou combinadas (ausência da fruta característica e presença de vegetal estranho; ausência da fruta e presença de fungo; presença de vegetal estranho e de fungo; ausência da fruta característica e presença de vegetal estranho e fungo).

Baseando-se na Portaria $n^{\circ} 2 / 85$ [3], que prevê a adição de ingredientes opcionais, como as frutas na forma de polpas, pedaços e sucos e/ou outras, devendo sempre estar nominalmente relacionadas nos dizeres de rotulagem, constituem fraudes tanto a constatação da ausência da(s) fruta(s) característica(s), como a identificação de vegetais não relacionados (vegetais estranhos).

Do total das amostras de iogurtes analisadas, 5,8\% não continham a fruta característica, incluindo os produtos contendo duas ou mais frutas, onde somente uma das frutas não foi identificada. Na Figura 1 podem ser observadas as percentagens de amostras de iogurtes analisadas segundo os parâmetros histológicos.

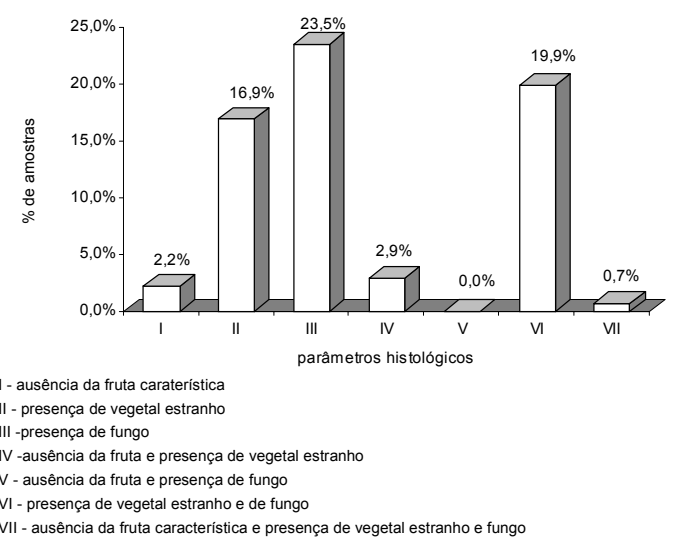

FIGURA 1. Porcentagens de amostras de iogurtes com frutas, segundo a avaliação microscópica. SP, 1999.

Das oito marcas analisadas, a maior porcentagem de fraudes ocorreu devido à presença de vegetal estranho em $16,9 \%$ das amostras (Figura 1), com o maior percentual de amostras da marca C, 35,3\% (Tabela 3). Além da fraude, em $19,9 \%$ das amostras também foi constatada a presença de fungos (Figura 1), correspondendo a $41,2 \%$ das amostras da marca $E, 29,4 \%$ da marca A, 23,5\% tanto para a marca $F$, como para a $G$, $17,6 \%$ para a marca $D$ e $11,8 \%$ para cada uma das marcas B e H (Tabela 3). Entre os vegetais estranhos, a maior ocorrência foi para a cúrcuma (Curcuma longa) e o urucum (Bixa orellana), provavelmente utilizados como corantes naturais, mas não declarados no rótulo.

$\mathrm{Na}$ avaliação microscópica a maior ocorrência foi a presença de fungos, verificada em $44,1 \%$ das amostras analisadas, sendo que $23,5 \%$ (Figura 1) só continham fungos e as demais estavam associadas à presença de fraudes. Verifica-se que a maior ocorrência de fungos foi em $53,0 \%$ das amostras da marca $\mathrm{H}$ seguida das marcas C e G, com $41,2 \%$ das amostras contendo fungo (Tabela 3). A marca $E$ apresentou o maior percentual das amostras, 41,2\%, contendo vegetal estranho e fungo (Tabela 3).

A identificação de hifas nas estruturas celulares das frutas é um indicativo do uso de matéria-prima avariada, demonstrando que quando utilizadas no processamento necessitam de maior controle de qualidade. Destacam-se entre as frutas analisadas, a framboesa e o morango com grande incidência de fungos, talvez por serem mais susceptíveis à deterioração. Aliadas à utilização de matéria-prima avariada, as condições inadequadas de processamento também contribuem para aumentar a incidência de fungos nas frutas. Pelo fato de não ter sido detectada a presença de fungos em nenhuma amostra de iogurte $(0,0 \%)$ que foi fraudada por não conter a fruta característica (Figura 1), pode-se justificar a presença de fungos em amostras quando da utilização de frutas avariadas. 
Mesmo que no processamento das frutas a serem adicionadas ao iogurte, conste o tratamento térmico ou asséptico como forma de destruição de fungos e outros microrganismos, tornando-os inviáveis, a análise microscópica pode indicar se foram utilizadas frutas deterioradas pela identificação de fungos filamentosos presentes nas estruturas celulares das frutas.

Pela Tabela 3, verifica-se que a marca G apresenta o maior percentual de amostras $(94,0 \%)$ em desacordo na avaliação microscópica, pela presença de vegetal estranho em $29,4 \%$, por fungos em $41,2 \%$ e pela presença de vegetal estranho e fungos em $23,5 \%$ das amostras.

A marca B apresentou amostras contendo o maior número de ocorrências, isto é, 6 das 7 estabelecidas na avaliação microscópica. Foi a única marca que apresentou uma amostra $(6,0 \%)$ contendo os dois tipos de fraudes e fungos (Tabela 3 ).

A marca $D$ apresentou a melhor avaliação microscópica, sendo que somente $1(6,0 \%)$ amostra continha vegetal estranho e $3(17,6 \%)$ apresentaram vegetal estranho e fungo (Tabela 3), indicando melhor controle na qualidade das frutas utilizadas como matéria-prima, em relação às demais marcas analisadas.

TABELA 3. Número e porcentagem de amostras de iogurtes com frutas, por marca codificada, segundo a avaliação microscópica. SP, 1999.

\begin{tabular}{|c|c|c|c|c|c|c|c|c|}
\hline \multirow{3}{*}{ Parâmetros histológicos } & \multicolumn{8}{|c|}{ Marcas } \\
\hline & A & в & C & D & $\mathrm{E}$ & $\mathrm{F}$ & G & $\mathrm{H}$ \\
\hline & $\mathrm{n}(\%)$ & $\mathrm{n}(\%)$ & $\mathrm{n}(\%)$ & $\mathrm{n}(\%)$ & $\mathrm{n}(\%)$ & n (\%) & $\mathrm{n}(\%)$ & $\mathrm{n}(\%)$ \\
\hline - Ausência da fruta & $0(0,0)$ & $2(11,8)$ & $0(0,0)$ & $0(0,0)$ & $1(6,0)$ & $0(0,0)$ & $0(0,0)$ & $0(0,0)$ \\
\hline $\begin{array}{l}\text { II - Presença de vegetal } \\
\text { estranho }\end{array}$ & $2(18,8)$ & $3(17,6)$ & $6(35,3)$ & $1(6,0)$ & $1(6,0)$ & $4(23,5)$ & $5(29,4)$ & $1(6,0)$ \\
\hline III - Presença de fungos & $4(23,5)$ & $2(11,8)$ & $7(41,2)$ & $0(0,0)$ & $0(0,0)$ & $3(17,6)$ & $7(41,2)$ & $9(53,0)$ \\
\hline $\begin{array}{l}\text { V - Ausência da fruta e } \\
\text { presença de vegetal } \\
\text { estranho }\end{array}$ & $0(0,0)$ & $1(6,0)$ & $0(0,0)$ & $0(0,0)$ & $3(17,6)$ & $0(0,0)$ & $0(0,0)$ & $0(0,0)$ \\
\hline $\begin{array}{l}V \text { - Ausência da fruta e } \\
\text { presença de fungo }\end{array}$ & $0(0,0)$ & $0(0,0)$ & $0(0,0)$ & $0(0,0)$ & $0(0,0)$ & $0(0,0)$ & $0(0,0)$ & $0(0,0)$ \\
\hline $\begin{array}{l}\text { VI - Presença de } \\
\text { vegetal estranho e } \\
\text { de fungo }\end{array}$ & $5(29,4)$ & $2(11,8)$ & $0(0,0)$ & $3(17,6)$ & $7(41,2)$ & $4(23,5)$ & $4(23,5)$ & $2(11,8)$ \\
\hline $\begin{array}{r}\mathrm{VII}-\text { - Ausência da fruta e } \\
\text { presenç̧a de vegetal } \\
\text { estranho e de fungo }\end{array}$ & $0(0,0)$ & $1(6,0)$ & $0(0,0)$ & $0(0,0)$ & $0(0,0)$ & $0(0,0)$ & $0(0,0)$ & $0(0,0)$ \\
\hline Total & $11(64,7)$ & $11(64,7)$ & $13(76,5)$ & $4(23,5)$ & $12(70,6)$ & $11(64,7)$ & $16(94,0)$ & $12(70,6)$ \\
\hline
\end{tabular}

$\mathrm{n}=$ número $(\%)=$ porcentagem

$\mathrm{Na}$ análise microbiológica, as amostras de todas as diferentes marcas de iogurtes com frutas, apresentaram coagulação do leite estéril em até a diluição $10^{-7}$, mesmo aquelas que apresentaram apenas cocos Grampositivos. Com relação à coloração de Gram, revelaram a presença de cocos Gram-positivos, em até a diluição $10^{-7}$, em $100 \%$ das amostras das marcas $B, C$, $D, F, G$ e $H$; em $87,5 \%$ da marca $A$ e em $92,3 \%$ da marca E. A presença de bacilos Gram-positivos em até a diluição $10^{-7}$ foi verificada em $25 \%$ da marca $A$; em $83,3 \%$ da marca $\mathrm{B} ; 22,2 \%$ da marca $\mathrm{C} ; 84,6 \%$ da marca $E ; 68,7 \%$ da marca $F ; 73,3 \%$ da marca $G$ e $0 \%$ nas marcas $\mathrm{D}$ e $\mathrm{H}$.

A legislação brasileira tem se referido apenas à viabilidade e abundância das bactérias lácticas em iogur- tes, sem estabelecer um valor mínimo para a contagem. A Recomendação Mercosul n 31/97 [5] passa a estabelecer um limite mínimo para as bactérias láticas totais como sendo de $10^{7} \mathrm{UFC} / \mathrm{mL}$, determinando que esses microrganismos específicos devam ser viáveis, ativos e abundantes no produto final e durante seu prazo de validade. Segundo ANDERSON [2], para que a qualidade do iogurte seja garantida, o número de colônias de $L$. bulgaricus e $S$. thermophilus, individualmente, não deve ser inferior a $10^{7}$ colônias por grama ou $\mathrm{mL}$.

$\mathrm{Na}$ contagem de estreptococos e de lactobacilos, cujos resultados são apresentados na Tabela 4, tomouse como referência o número de colônias de estreptococos e lactobacilos, individualmente, como sendo maior ou igual a $10^{7}$ colônias por grama ou $\mathrm{mL}[2,5]$. Verificase que $66,7 \%$ das amostras de iogurtes da marca B; $33,3 \%$ da marca C; $50,0 \%$ da marca $\mathrm{F}$ e $93,3 \%$ da marca $\mathrm{G}$ apresentaram quantidades iguais ou superiores a $10^{7} \mathrm{UFC} / \mathrm{mL}$, para estreptococos e lactobacilos (Tabela 4). As demais marcas apresentaram quantidades inferiores ao limite mínimo $\left(10^{7} \mathrm{UFC} / \mathrm{mL}\right)$ indicado pela $\mathrm{Re}-$ comendação Mercosul n $31 / 97$ [5]. No total, 31,7\% das amostras apresentaram o limite mínimo para estreptococos e lactobacilos, $51,0 \%$, apenas para estreptococos, 10,6\%, para lactobacilos e $6,7 \%$ não apresentaram o limite mínimo.

TABELA 4. Número e porcentagem de amostras de iogurtes com frutas, por marca codificada, das contagens de estreptococos e de lactobacilos. SP, 1999.

\begin{tabular}{|c|c|c|c|c|c|c|c|c|c|}
\hline \multicolumn{2}{|c|}{ Microrganismos } & \multicolumn{8}{|c|}{ Positividade de amostras (\%) por marca codificada } \\
\hline $\begin{array}{l}\text { Estrep- } \\
\text { tococos }\end{array}$ & $\begin{array}{l}\text { Lacto- } \\
\text { bacilos }\end{array}$ & $\begin{array}{c}\mathrm{A} \\
\mathrm{n}(\%)\end{array}$ & $\begin{array}{c}B \\
n(\%)\end{array}$ & $\begin{array}{c}c \\
n(\%)\end{array}$ & $\begin{array}{c}D \\
n(\%)\end{array}$ & $\begin{array}{c}E \\
n(\%)\end{array}$ & $\begin{array}{c}F \\
n(\%)\end{array}$ & $\begin{array}{c}\mathrm{G} \\
\mathrm{n}(\%)\end{array}$ & $\begin{array}{c}\mathrm{H} \\
\mathrm{n}(\%)\end{array}$ \\
\hline$<10^{7}$ & $<10^{7}$ & $3(18,7)$ & $2(16,7)$ & $0(0,0)$ & $1(9,1)$ & $1(7,7)$ & $0(0,0)$ & $0(0,0)$ & $0(0,0)$ \\
\hline$<10^{7}$ & $\geq 10^{7}$ & $1(6,3)$ & $1(8,3)$ & $2(22,2)$ & $0(0,0)$ & $4(30,8)$ & $3(18,7)$ & $0(0,0)$ & $0(0,0)$ \\
\hline$\geq 10^{7}$ & $<10^{7}$ & $2(75,0)$ & $1(8,3)$ & $4(44,5)$ & $10(90,9)$ & $8(61,5)$ & $5(31,3)$ & $1(6,7)$ & $2(100,0)$ \\
\hline$\geq 10^{7}$ & $\geq 10^{7}$ & $0(0,0)$ & $8(66,7)$ & $3(33,3)$ & $0(0,0)$ & $0(0,0)$ & $8(50,0)$ & $14(93,3)$ & $0(0,0)$ \\
\hline
\end{tabular}

$\mathrm{n}=$ número $\quad(\%)=$ porcentagem

\section{4 - CONCLUSÕES}

A caracterização físico-química das oito diferentes marcas de iogurtes com frutas revelou que os teores das variáveis médias obtidos para os nutrientes podem ser considerados adequados, quando comparados aos requisitos indicados pela Recomendação Mercosul. Assim sendo, sugere-se que os resultados obtidos possam servir de base ao estabelecimento de parâmetros físico-químicos a serem regulamentados pela legislação brasileira.

Das 136 amostras de iogurtes com frutas analisadas quanto aos parâmetros histológicos, 46,2\% estavam em desacordo, segundo as informações declaradas na rotulagem, e 44,1\% indicaram a utilização de matéria-prima em condições higiênicas inadequadas.

Em relação às determinações microbiológicas, nenhuma das marcas apresentou, na totalidade das amos- 
tras analisadas, a quantidade mínima de bactérias láticas indicadas pela Recomendação Mercosul.

\section{5 - REFERÊNCIAS BIBLIOGRÁFICAS}

[1] ALAIS, CH. Ciência de la leche - Princípios de Técnica Lechera. Ed. Revertè. Trad. D.A.L. GODINA, Barcelona (España), p. 763-7, 1985.

[2] ANDERSON, M.D.R.P. Microbiologia Alimentaria - Metodologia Analítica para Alimentos y Bebidas. Ed. Diaz de Santos, España, p. 222-224, 1992.

[3] BRASIL. Leis, decretos, etc. Portaria $n^{\circ} 2$ de 10 de abril de 1985, da Secretaria de Inspeção de Produto Animal - SNDA, Diário Oficial da União, Brasília, 12 abr. 1985, Seç. II, p. 6952.

[4] BRASIL. Leis, decretos, etc. Decreto $n^{\circ} 2.224$ de 4 de junho de 1997, Diário Oficial da União, Brasília, 5 jun. 1997, Seç. I, p. 11555 (altera dispositivos do Dec. $n^{\circ} 30.691$ de 29 de março de $1952 \ldots$..).

[5] BRASIL. Leis, decretos, etc. Recomendação no 31 de 12 de junho de 1997 (Consulta Pública) - Regulamento Técnico Mercosur de Identidade e Qualidade de Leites Fermentados, Diário Oficial da União, Brasília, 3 jul 1997, Seç. 1, p. 14064. (Internalizada no Brasil - DIPOA/MA - Resolução $n^{\circ} 5$ de 13 de novembro de 2000 - republicada em 2/01/2001 - http://www.agricultura.gov.br/das/dipoa/ resolução leite fermentado.htm.

[6] CÓDIGO ALIMENTÁRIO ARGENTINO (actualizado). Resolução n 879 de 5 de junho de 1985, Buenos Aires, Argentina, Tomo I-A, Cap. VIII, Art. 576, p. 189-192.

[7] ÇON, A.H. et al.. Effets of different fruits and storage periods on microbiological qualities of fruit - flavored yogurt produced in Turkey. Journal of Food Protection, v. 59, n. 4, p. 402-406, 1996.

[8] DE ANGELIS, R.C. Fisiologia da Nutrição: Fundamentos para nutrição e para desnutrição. v. 1. São Paulo, Ed. EDART, USP, 1977, p. 44

[9] HOFFMANN, F.L.; PAGNOCCA, F.C.; FAZIO, M.L.S.; VINTURIM, T.M. logurte: Falta de cuidados altera qualidade microbiológica. Revista do Instituto Laticínios Cândido Tostes, v. 1, n. 4, p. 32-34, 1996.

[10] INSTITUTO ADOLFO LUTZ. Normas Analíticas do Instituto Adolfo Lutz: Métodos Químicos e Físicos para
Alimentos e Bebidas. São Paulo, IMESP, v. 3, p. 21-27, 44-6, 1985

[11] MANZANARES, A. Lácteos de alto consumo en Latinoamérica. Tecnologia Láctea Latinoamericana, v. 5, p. 31-39, 1996.

[12] MARTINS, J.F.P.; LUCHESE, R.H. Determinação da compatibilidade de crescimento associativo entre cepas de Lactobacillus bulgaricus e Streptococcus thermophilus. Revista do Instituto Laticínios Cândido Tostes, v. 43 , n. 256, p. 11-13, 1988.

[13] MINISTÉRIO DA AGRICULTURA. Secretaria Nacional de Defesa Agropecuária. Laboratório Nacional de Referência Animal (LANARA). Métodos Analíticos Oficiais para Controle de Produtos de Origem Animal e seus Ingredientes. II - Métodos Físicos e Químicos. Brasília, p. XVII - 1-6, 1981.

[14] MINISTÉRIO DA EDUCAÇÃO. Fundação de Assistência ao Estudante (FAE). Manual de Métodos Analíticos Oficiais de Controle de Qualidade. v. 3, Brasília, MEC, p. 122 (MT.01.07.04), 1988.

[15] NOGUEIRA, M.D.; RODRIGUES, R.M.M.S. Uso de tamis na identificação de elementos histológicos em iogurtes com polpa de fruta (s). Revista do Instituto Adolfo Lutz, v. 54, n. 2, p. 93-96, 1994.

[16] PERDIGON, G.; ALVAREZ, S.; VALDEZ, J.C. Acción de bacterias lácticas y yogur sobre la respuesta inmune: Sistémica, de mucosas y tumural. Tecnologia Láctea Latinoamericana, n. 2, p. 26-30, 1995.

[17] PORTER, J.W.G. Leche y productos lácteos. Trad. J.L.B. ESCALADA, Ed. Acribia, Zaragoza (España), p. 71-74, 1981.

[18] VEDAMUTHU, E.R. The yogurt story - past, present and future. Part. V. Dairy, Food and Environmental Sanitation, v. 11, n. 8, p. 444-446, 1991.

[19] VEDAMUTHU, E.R. The yogurt story - past, present and future. Part. VI. Dairy, Food and Environmental Sanitation, v. 11, n. 9, p. 513-514, 1991.

[20] VEISSEYRE, R. Lactologia Técnica - Composición, recogida, tratamiento y transformatión de la leche. Ed. Acribia, Zaragoza (España), p. 288-291, 1988.

[21] VOSNIAKOS, F. et al.. Effect of 131 I on lactic acid microflora of yoghurt. Dairy Food and Environmental Sanitation, v. 8, n 11, p. 433-435, 1991. 